\title{
OPTIMALISASI KEMAMPUAN MENGENAL BILANGAN ANAK TUNAGRAHITA MELALUI PENGGUNAAN MEDIA GEMISTEK DI SLB NEGERI 1 BENGKULU SELATAN
}

\author{
Parmi $^{1}$ dan Irwandi ${ }^{2}$ \\ ${ }^{1}$ Guru Sekolah Luar Biasa Negeri 1 Bengkulu Selatan \\ ${ }^{2}$ Program Pascsarjana Magister Pendidikan Biologi Universitas Muhammadiyah Bengkulu \\ Kampus 4 Jl. Adam Malik KM. 9 Kota Bengkulu
}

\begin{abstract}
The purpose of this study is to help mentally retarded children in fluency in learning the ability to recognize numbers. It is expected that the use of Gemistekakan media will make mentally retarded children better in carrying out their learning activities. The subjects in this study were children who sat in IIC SLB Negeri 1 Bengkulu Selatan class totaling 6 people. The results of the study are Gemistek media able to help mentally retarded children to smooth the ability to learn to recognize numbers, besides this media is also cheap and interesting so that it can be developed and reproduced by itself.
\end{abstract}

Keywords: learning, numbers, mental retardation.

Abstrak: Tujuan penelitian ini adalah untuk membantu anak tunagrahita dalam kelancaran kemampuan belajar mengenal bilangan. Diharapkan penggunaan media Gemistekakan membuat anak tunagrahita lebih baik lagi dalam melaksanakan aktivitas pembelajaran mereka. Subjek dalam penelitian ini adalah anak yang duduk di kelas IIC SLB Negeri 1 Bengkulu Selatan berjumlah 6 orang. Hasil dari penelitian adalah media Gemistek mampu membantu anak tunagrahita untuk kelancaran kemampuan belajar mengenal bilangan, selain itu media ini juga murah dan menarik sehingga bisa dikembangkan dan di perbanyak sendiri.

Kata Kunci: Media Gemistek, belajar, bilangan, tunagrahita.

\section{PENDAHULUAN}

Pendidikan adalah proses pembelajaran yang terencana melalui pengajaran, pelatihan atau penelitian untuk menciptakan generasi penerus bangsa yang memiliki kecerdasan pengetahuan, spiritual, kepribadian, ataupun keterampilan dalam bersosialisasi di masyarakat. Dalam Undang-Undang no.20 tahun 2003 tentang Sistem Pendidikan Nasional pasal 5 ayat disebutkan bahwa, "Warga negara yang memiliki kelainan fisik, emosional, mental, intelektual, dan/atau sosial berhak memperoleh pendidikan khusus". Berdasarkan landasan yuridis tersebut, pendidikan ditujukkan untuk seluruh warga negara tidak terkecuali anak berkebutuhan khusus.

Anak berkebutuhan khusus memiliki hak dan kewajiban yang sama seperti anak pada umumnya, sehingga mereka juga mempunyai kesempatan yang sama untuk belajar dan duduk di bangku sekolah. Salah satu jenis anak berkebutuhan khusus adalah tunagrahita. Menurut Yusuf (2009:6), "Tunagrahita adalah anak yang secara nyata mengalami hambatan dan keterbelakangan perkembangan mental intelektual di bawah rata-rata sehingga mengalami kesulitan dalam menyelesaikan tugas-tugasnya". Definisi tersebut dapat diketahui bahwa intelegensi anak tunagrahita tergolong rendah atau di bawah rata-rata, mengakibatkan anak tunagrahita mengalami hambatan dalam menjalankanberbagai aktivitas atau kegiatan seharihari, hambatan dalam pembelajaran akademik, sosial dan sebagainya.

Kondisi intelegensi anak tunagrahita yang tergolong rendah menyebabkan beberapa hambatan dan permasalahan. Menurut Mumpuniarti (2005:49) masalah yang ditimbulkan sebagai dampak ketunagrahitaan antara lain, (a) masalah kesulitan dalam kehidupan sehari-hari; (b) masalah penyesuaian diri; (c) masalah penyaluran tempat kerja; (d) masalah kesulitan belajar; (e) masalah gangguan kepribadian dan emosi; (f) masalah pemanfaatan waktu luang. Dari beberapa masalah seperti yang telah disebutkan masalah yang menjadi perhatian adalah kesulitan dalam kehidupan seharihari, pengembangan diri, adaptasi dengan lingkungan sosial, serta emosinya. Oleh karena itu, anak tunagrahita membutuhkan pembelajaran kompensatoris ditinjau dari berbagai hambatan dan masalah yang dimilikinya.

Sekolah luar biasa (SLB) Negeri 1 Bengkulu Selatan adalah satu-satunya SLB yang ada di kabupaten Bengkulu Selatan.Anak tunagrahita yang dimiliki SLB Negeri 1 Bengkulu Selatan sekitar $80 \%$ dari semua jenis anak berkebutuhan khusus. Hampir seluruh anak tunagrahita di SLB Negeri 1 Bengkulu Selatan memiliki hambatan dalam belajar akademik seperti dalam bidang Matematika, hambatan awal yang dialami oleh anak tersebut adalah dalam mengenal bilangan. Dampak yang ditimbulkan akibat belum mampu mengenal bilangan adalah mereka sulit untuk beradaptasi dengan lingkungan sekitarnya dan cenderung rendah diri dalam bergaul dengan masyarakat di sekitarnya. Oleh karena itu anak tunagrahita perlu mendapat bimbingan dalam awal dalam pembelajaran matematika yaitu mengenal bilangan agar mampu 
berhitung sederhana untuk bekal bersosialisasi dengan lingkungan sekitarnya.

Adanya kesulitan anak tunagrahita dalam mengenal bilangan, mendorong peneliti untuk membuat suatu inovasi pembelajaran yang kreatif dan menyenangkan bagi anak, agar mereka tidak merasa bosan dan mudah untuk menerima pembelajaran. Banyak cara yang dapat digunakan untuk mengenalkan bilangan pada anak tunagrahita salah satunya adalah dengan media Gemistek. Gemistek merupakan akronim dari Gelas Mineral Stik Es Krim. Gemistek ini adalah media yang berasal dari barangbarang bekas yang ada di sekitar guru dananak, sehingga sangatlah mudah, ekonomis dan efisien untuk membuatnya, apabila ingin memperbanyak pembuat media Gemistek untuk pembelajaran di SLB Negeri 1 Bengkulu Selatan sangatlah terjangkau dan bisa dibuat oleh siapapun. Berdasarkan permasalahan di atas penulis tertarik untuk melakukan penelitian dengan menggunakan media Gemistek. Penggunaan media Gemistek diharapkan dapat mempermudah guru meningkatkan kemampuan mengenal bilangan untuk anak tunagrahita agar dapat berhitung sederhana.

\section{METODE}

Kegiatan ini dilakukan pada anak tunagrahita kelas II C di SLB Negeri 1 Bengkulu Selatan, Jalan Kayu Kunyit, Kecamatan Manna, Kabupaten Bengkulu Selatan. Kegiatan ini dilaksanakan pada Bulan Januari 2018 di minggu ke 3 dan proses pembelajaran media Gemistek dilakukan sebanyak 3 kali pertemuan.

Media Gemistek yaitu alat peraga yang digunakan untuk mempermudah penyampaian materi pengenalan bilangan. Media Gemistek terbuat dari bahan bekas kardus, gelas air mineral dan stik es krim. Media Gemistek belum pernah digunakan sebagai media pembelajaran. Tujuan dari pembuatan Media Gemistek ini adalah untuk membantu memudahkan anak tunagrahita belajar mengenal bilangan.

Cara penggunaan media Gemistek adalah sebagai berikut:

1. Siapkan Media Gemistek yang telah di buat.

2. Guru membagikan stik bola kepada siswa sampai habis.

3. Guru menghampiri siswa dengan membawa kotak yang telah berisi gelas mineral.

4. Siswa secara bergiliran memasukkan stik bola ke dalam gelas mineral yang ada pada kotak sesuai dengan stik bilangan yang tertera pada gelas mineral tersebut.

5. Kegiatan ini berlangsung sampai stik yang dipegang oleh siswa habis.

6. Demikianlah cara penggunaan Media Gemistek dalam proses pembelajaran.

Dalam proses pembelajaran yang dilaksanakan 3 kali pertemuan, anak perlahan mampu mengenal bilangan walaupun masih ada anak yang perlu bimbingan dalam mengenal bilangan tersebut, akan tetapi sudah ada perubahan dari kemampuan awal anak.

Untuk menguji hasil penggunaan media Gemistek penulis melakukan pengumpulan data dengan cara tes. Dalam jenisnya tes dibagi dalam beberapa macam, Djaali dan Muljono (2007: 11) menjelaskan, jika tes ditinjau dari cara mengajukan pertanyaan, tes digolongkan dalam tiga macam yaitu, tes tertulis, tes lisan dan tes perbuatan (tes praktik). Dalam kegiatan ini peneliti menggunakan tes lisan, hal ini dikarenakan subjeknya adalah anak tunagrahita kelas rendah yang belum mampu untuk diberikan tes tertulis. Menurut Djaali dan Muljono (2007: 11) Tes lisan yaitu dimana dalam pelaksanaan tes dalam mengajukan butir-butir pertanyaan secara lisan dan peserta tes memberi jawaban secara lisan pula. Tes lisan ini digunakan untuk mengetahui pemahaman pengenalan bilangan pada anak, dan mengukur tingkat perubahan yang dialami anak dari kemampuan awal anak dalam mengenal bilangan.

\section{HASIL PENELITIAN DAN PEMBAHASAN Hasil}

Kegiatan yang dilaksanakan bertujuan untuk mengetahui penggunaan Media Gemistek dalam mengoptimalkan kemampuan mengenal bilangan pada anak tunagrahita kelas IIC di SLB Negeri 1 Bengkulu Selatan. Kegiatan ini bertempat di SLB Negeri 1 Bengkulu Selatan jalan Kayu Kunyit, Kecamatan Manna, Kabupaten Bengkulu Selatan. Kegiatan dilaksanakan dalam proses pembelajaran di minggu ketiga bulan Januari selama 3 kali pertemuan.

Pada pertemuan pertama tanggal 21 Januari 2018, subjek AN masih membutuhkan bimbingan dalam mengenal bilangan 1-4 dan belum mengenal bilangan 5-10 dengan nilai 46,7. Subjek RA masih membutuhkan bimbingan dalam mengenal bilangan 1-7 dan belum mengenal bilangan 8-10 dengan nilai 56. Subjek VA masih membutuhkan bimbingan mengenal angka 1-5 dan belum mengenal angka 6-10 dengan nilai 50. Subjek ME masih membutuhkan bimbingan mengenal angka 1-4 dan belum mengenal bilangan 5-10 dengan nilai 46,7. Sedangkan subjek DE dan KA masih belum mengenal sama sekali bilangan 1-10 dengan nilai 33 .

Pertemuan kedua dilaksanakan tanggal 22 Januari 2018, subjek ANmengalami peningkatan dia sudah dapat secara mandiri mengenal angka 1-4 dan mengenal angka 5-10 dengan bimbingan dengan nilai 80. Subjek DE sudah dapat mengenal angka 1-3 dengan bimbingan dengan nilai 43. Subjek RA sudah mengenal sendiri tanpa bantuan bilangan 1-5 dan mengenal dengan bimbingan bilangan 6-10 dengan nilai 83. Subjek VA sudah mengenal tanpa bimbingan 1-5 dan dengan bimbingan bilangan 6-10 dengan nilai 83.Subjek ME sudah mengenal dengan angka 1-3 tanpa bimbingan dan mengenal angka 4-7 dengan bimbingan denga nilai 67.Subjek KA sudah mengenal dengan bimbingan bilangan 1-5 dengan nilai 50 . Pertemuan ketiga dilaksanakan tanggal 23 Januari 2018 Subjek AN, RA dan VA sudah mengenal bilangan 1-10 tanpa bimbingan dengan nilai 
100.Subjek DE mengenal bilangan 1-6 dengan bimbingan dengan nilai 53. Subjek ME mengenal tanpa bimbingan bilangan 1-5 dan 6-10 dengan bimbingan dengan nilai 83 dan subjek KA mengenal bilangan 1-7 dengan bimbingan dengan nilai 57 .
Dengan rincian perubahan nilai dalam diagram berikut

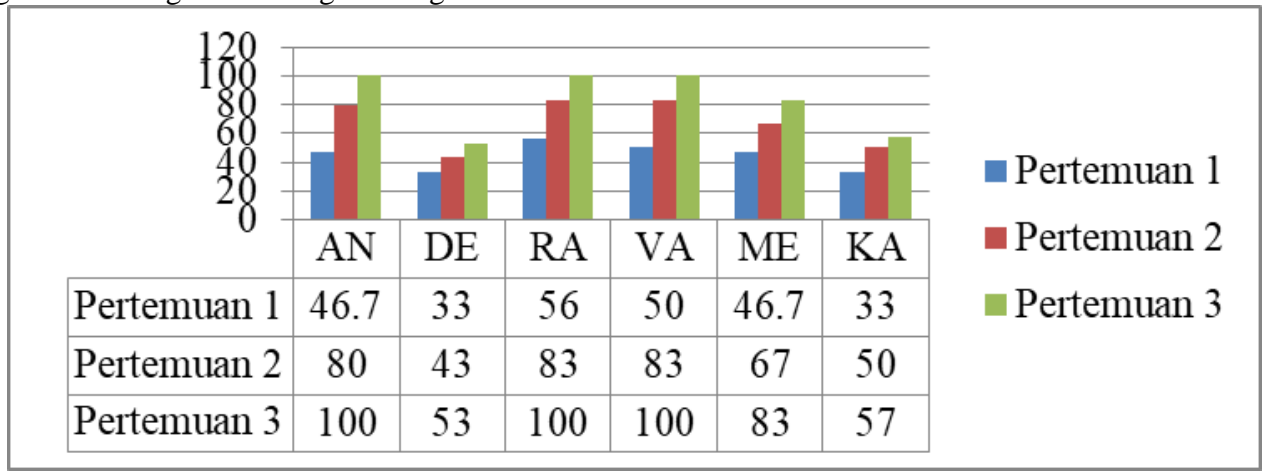

Gambar 1. Grafik Perubahan Kemampuan kognitif subjek AN, DE, RA, VA, ME, dan KA pada pertemuan 1,2 dan 3

Berdasarkan hasil penelitian terhadap subjek AN, DE, RA, VA, ME, dan KA menunjukkan bahwa penggunaan Media Gemistek mampu meningkatkan kemampuan mengenal bilangan pada anak tunagrahita kelas IIC di SLB Negeri 1 Bengkulu Selatan. Hal ini terbukti dengan adanya peningkatan kemampuan subjek dari pertemuan pertama ke pertemuan selanjutnya.

Pada proses awal pembelajaran menggunakan Media Gemistek materi pengenalan bilangan, anak sangat antusias dan riang gembira karena guru membawa media yang berwarna warni menarik perhatian mereka, serta anak termotivasi untuk lebih giat belajar mengenal bilangan dengan media tersebut. Media Gemistek sangat mudah digunakan, menarik dengan warna-warna mencoloknya dan sangat cocok untuk anak tunagrahita, sehingga suasana pembelajaran di kelas lebih hidup dan menyenangkan. Tidak ada lagi suasana kaku, karena dalam proses pembelajaran bisa diselingi dengan bernyanyi seperti bernyayi lagu "Balon ku","Dua Mata Saya" atau disesuaikan dengan Media Gemistek.

Media Gemistek ini membantu anak tunagrahita untuk memudahkan mereka dalam belajar mengenal bilangan. Alat peraga ini dibuat agar menjadikan proses pembelajaran di kelas menjadi lebih menyenangkan. Saat menggunakan Media Gemistek anak tunagrahita terlibat langsung dalam proses pembelajaran. Pembelajaran menjadi lebih bermakna dan berkesan bagi anak tunagrahita.

$$
\text { Setelah dilakukan pembelajaran }
$$
menggunakan media Gemistek, maka penulisi melakukan evaluasi dengan menggunakan teknik pengumpulan data berupa tes dan yang digunakan jenis tes lisan. Evaluasi ini dilakukan untuk mengetahui pemahaman anak mengenal lambang bilangan. Tes dilakukan dengan cara guru bertanya satu persatu dengan anak untuk menyebutkan bilangan yang ditunjuk oleh penulis atau mengangkat stik berdasarkan bilangan yang disebutkan oleh penulis dan dimasukkan ke dalam gelas mineral bekas sesuai dengan bilangannya.

Hasil pengumpulan data tes lisan oleh penulis bahwa subjek AN, DE, RA, VA, ME, dan KA mengalami peningkatan kemampuan dalam mengenal bilangan dari kemampuan awal yang mereka miliki. Salah satu hal yang diharapkan dalam pencapaian pembelajaran adalah agar anak mampu berhitung sederhana, khususnya untuk mengenal bilangan, dan mampu menyampaikan gagasannya. Anak tunagrahita mempunyai kemampuan intelektual yang rendah, sehingga diperlukannya Media Gemistek untuk membantu anak dalam mengikuti pembelajaran. Arief S. Sadirman Dkk (2003:6) mengatakan bahwa "Media adalah perantara atau pengantar pesan dari pengirim ke penerima pesan". Sementara Ahmad Rohani (1997: 3) mengatakan bahwa "Media adalah segala sesuatu yang dapat diindrakan yang berfungsi sebagai peranatara/sarana/alat untuk proses komunikasi (proses belajar mengajar)". Media adalah alat yang menyampaikan atau menggambarkan pesan-pesan pengajaran.

Oleh karena itu, media adalah alat bantu apa saja yang dapat dijadikan sebagai penyalur pesan guna mencapai tujuan pengajaran yang diinginkan dan membantu anak dalam memperjelas materi yang disampaikan dalam proses pembelajaran, salah satu media yang dapat membantu anak tunagrahita adalah Media Gemistek.

Berdasarkan hasil pengumpulan data dan pembahasan ditemukan bahwa penggunaanMedia Gemistek mampu untuk meningkatkan kemampuan belajar anak tunagrahita khususnya untuk materi mengenal bilangan. Dalam pengamatan, terlihat 
bahwa anak tunagrahita merasa terbantu dengan adanya media Gemistek ini.

\section{SIMPULAN}

Berdasarkan pengalaman penulis bahwa penggunaan Media Gemistek dapat mengoptimalkan kemampuan mengenal bilangan pada anak tunagrahita di SLB Negeri 1 Bengkulu Selatan.

\section{DAFTAR PUSTAKA}

Amir, M.T. 2010. Inovasi pendidikan melalui problem based learning. Prenada Media Group

Badaruddin.M. 2015. Pengaruh Model Pembelajaran Problem Based Learning (PBL) Terhadap Motivasi Dan Hasil Belajar Ipa Biologi Siswa MTS NURUL HUDASRIMULYO NGAWEN BLORA. Program Sarjana Pendidikan Yogyakarta. Yogyakarta

Bekti Wulandari. 2013. Pengaruh Problem-Based Learning Terhadap Hasil Belajar Ditinjau dari Motivasi Belajar Plc Di SMK. Jurnal Pendidikan Vokasi, Vol 3. No 2.

Djamarah. 2010. Strategi belajar mengajar. Jakarta: PT Rineka Cipta

Hamdani. 2011. Strategi Belajar Mengajar. Pustaka Jaya Bandung

Herlina. 2016. Pengaruh Model Problem Based Learning Dan Motivasiberprestasi Terhadap Hasil Belajar Siswa Pada Mata Pelajaran Biologi Di Kelas Xi Ipa Man 2 Model Palu.

Program Studi Magister Sains Pascasarjana Universitas Tadulako)

Irwandi. 2010. Strategi Pembelajaran biologi berbasi kontekstual. Universitas Muhammadiyah Bengkulu. Bengkulu Pers.

Lasmawan. 2010. Pengaruh model pembelajaran berbasis masalah terhadap kemampuan berfikir kritis siswa, motivasi belajar, dan hasil belajar IPS siswa VII SMP N 1 Aikmei. E-Journal Program Pascasarjana Universitas Pendidikan Ganesha Program Studi Pendidikan Dasar 3.

Lufri. 2007. Kiat Memahami dan Melakukan Penelitian. UNP Press

Mujiono \& Dimyati. 2012. Belajar \& pembelajaran. Jakarta: PT. Rineka Putra
Muspita. Zalia, Wayan. Lasmawan, Sariyasa. 2013. Pengaruh Model Pembelajaran Berbasis Masalah Terhadap Kemampuan Berpikir Kritis, Motivasi Belajar, Dan Hasil Belajar IPS Siswa Kelas VII SMPN 1 Aikmel. Jurnal pendidikan ganesha: Vol 3 No 3

Ngalimun. 2012. Startegi dan Model Pembelajaran. Aswaja Pressindo. Banjarmasin

Nurbaiti, S.I, Irawati, R \& Lichteria R. 2016. Pengaruh Pendekatan Problem Based Learning Terahadap Kemampuan Komunikasi Matematis Dan Motivasi Belajar Siswa. Jurnal Pena Ilmiah: Vol. 1, No. 1.

Riduwan. 2009. Dasar-dasar statistika. ALFABETA. Bandung

Risqi, HK, Zubaidah, S Handayani. N. 2015 pengaruh problem based learning terhadap motivasi dan hasil belajarb siswa kelas VII SMP Brawijaya Smart School Malang.

Rusman. 2010. Model-Model Pembelajaran Mengembangkan Profesional Guru. Jakarta: PT Rajagrafindo Persada

Sanjaya, Wina. 2011. Strategi Pmbelajaran Mengembangkan Guru. Jakarta: PT Kencana Prenada Media

Sardiman. 2012. Interaksi \& Motivasi Belajar Mengajar. Jakarta: Rajawali Pers.

Suprijono, A. 2009. Cooperative Learning teori dan aplikasi PAIKEM. PT. Pustaka Belajar. Yogyakarta.

Tirtarahardja. U \& Sulo, L. 2005. Pengantar pendidikan. PT. Rineka Cipta. Jakarta

Vebriyanti Dwi Anggraini. 2013. Problem Based Learning, Motivasi Belajar, Kemampuan Awal, Dan Hasil Belajar Siswa Smk. Universitas Negeri Malang. Malang

Warsita. 2008. Teknologi Pembelajaran Landasan Teori \& Aplikasinya. PT. Rineka Cipta. Jakarta

Wulandari. B dan Surjono. HD. 2013. Pengaruh probem based learning terhadap hasil belajar ditinjau dari motivasi belajar PLC di SMK. Vol 3, Juni 2013. Hal 181-182

Yolida. B, Monalia. C, Oktarina. H, dan Karyanti. 2014. Pengaruh Model Pembelajaran Problem Based Learning (PBL) Terhadap Hasil Belajar Biologi Siswa Vol 4, N0 2 (2016) Hal 
